\title{
Coupling of Exothermic and Endothermic Hydrogen Storage Materials
}

\author{
Kriston P. Brooks, Mark E. Bowden, Abhijeet J. Karkamkar, Adrian Y. Houghton, S. Thomas Autrey
}

Pacific Northwest National Laboratory, 902 Battelle Boulevard, Richland, WA 99352, United States

* Corresponding author. Tel: +1 5093724343

E-mail addresses: Kriston.brooks@pnnl.gov (K.P. Brooks), Mark.bowden@pnnl.gov (M. E. Bowden), Abhi.Karhamkar@pnnl.gov (A. J. Karkamkar), Adrian.houghton@pnnl.gov (A. Y. Houghton),

Tom.autrey@pnnl.gov (S. T. Autrey)

${ }^{1}$ Tel: +1 5093717816

${ }^{2}$ Tel: +15093724973

${ }^{3}$ Tel: +15093726837

${ }^{4}$ Tel: +15093753792

\begin{abstract}
Chemical hydrogen storage (CHS) materials are a high-storage-density alternative to the gaseous compressed hydrogen currently used to provide hydrogen for fuel cell vehicles. One of the challenges of CHS materials is addressing the energy barriers required to break the chemical bonds and release the hydrogen. Coupling CHS reactions that are endothermic and exothermic during dehydrogenation can improve onboard energy efficiency and thermal control for the system, making such materials viable. Acceptable coupling between reactions requires both thermodynamic and kinetic considerations. In this work, models were developed to predict the reaction enthalpy and rate required to achieve high conversions for both reactions based on experimental measurements. Modeling results show that the coupling efficiency of exothermic and endothermic reactions is more sensitive to the ratio of the exothermic and endothermic enthalpies than to the ratio of the rates of the two steps. Modeling results also show that a slower endothermic step rate is desirable to permit sufficient heating of the reactor by the exothermic step. We look at two examples of a sequential and parallel reaction scheme and provide some of the first published insight into the required temperature range to maximize the hydrogen release from 1,2-BN cyclohexane and indoline.
\end{abstract}

\section{Introduction}

Safe and efficient storage and delivery of hydrogen is essential to the development of a hydrogen-based energy infrastructure. Storage of hydrogen as a compressed gas is the current state-of-the-art. However, gaseous hydrogen has low gravimetric and volumetric densities and as a result must be stored at high pressures (up to 700 bar) to provide acceptable storage media, ca. $56 \mathrm{~g}$ hydrogen liter ${ }^{-1}$ material basis, for vehicular applications. In an effort to improve the gravimetric and volumetric storage density of hydrogen, a variety of chemical hydrogen storage (CHS) materials are under development [1-12]. CHS materials are hydrogen-bearing materials that release hydrogen when chemical bonds are broken. 
Efforts in developing these materials have focused on obtaining high hydrogen storage capacities and favorable kinetics for hydrogen release while maintaining stability under near ambient conditions. ${ }^{1}$ In addition, the thermodynamics of the both the hydrogenation and dehydrogenation reactions must be acceptable. Materials that dehydrogenate endothermically have historically been selected given that regeneration is reversible with the addition of hydrogen at elevated pressure. However, the need to burn some of the hydrogen generated to provide to the temperatures required for hydrogen release makes it difficult for these materials to meet onboard efficiency targets. An ideal hydrogen storage material can be dehydrogenated onboard a vehicle or device without using large amounts of energy to initiate the hydrogen release reaction while being regenerated without excessive energy addition requirements. Unfortunately, achieving both of these targets with a single material has been elusive.

It is possible that by coupling the exothermic and endothermic reactions, the overall energy required during dehydrogenation can be reduced to acceptable levels to meet the onboard efficiency target. Furthermore, during regeneration, the energy produced by the hydrogenation from one reaction can compensate for the energy penalty required by the other. These so-called coupled exothermic and endothermic reactions are similar to what has been done industrially in reactions described as autothermal, but to our knowledge, the reactions have not been investigated quantitatively for onboard hydrogen storage materials. One significant industrial application of an auto-thermal reaction is combining steam reforming and partial oxidation to produce hydrogen $[13,14]$. The goal of all these autothermal or coupled reactions is for the overall reaction to be nearly thermally neutral. In addition to reducing the amount of heat required for the endothermic reaction, coupling the two reactions also can decrease the maximum temperature generated by the exothermic reaction, thus providing a mechanism to prevent runaway thermal events and/or reduce external cooling requirements.

Coupled exothermic and endothermic reactions can be classified in several ways-recuperative coupling, regenerative coupling, and direct coupling [15]. Recuperative coupling involves reactions that are segregated, usually occurring in two separate reactors with heat transfer occurring between the walls. For regenerative coupling, both reactions occur within the same reactor but at different times during two cycles. The first cycle may be a combustion process that heats the catalyst bed, while during the second cycle, the flow is changed, and the endotherm reaction uses heat stored in the catalyst bed. In direct coupling, both reactions occur simultaneously in the same bed.

Direct coupling of exothermic and endothermic reactions with hydrogen storage materials has been discussed previously. This coupling can occur with both functions on a single carrier [16] or by a mixture of two materials for an overall thermally neutral reaction [17]. Cooper et al. [16] proposed a process with two separate, thermally coupled reactors. They found that perhydrofluorene is dehydrogenated in an endothermic reaction to produce 6 moles of hydrogen and fluorene. Then, subsequent addition of air to the reaction stream partially oxidizes fluorene to fluorenone in an exothermic reaction. The heat from the second reaction could then be transferred to the dehydrogenation reactor to drive this endothermic process. In this case, both reactions would occur at approximately $225^{\circ} \mathrm{C}$.

\footnotetext{
${ }^{1} \mathrm{~A}$ CHS material must remain stable up to $60^{\circ} \mathrm{C}$ with losses of less than $0.05 \mathrm{~g} \mathrm{~h}^{-1} \mathrm{~kg}^{-1}$ of the stored hydrogen.
} 
Wechsler et al. [17] demonstrated a mixture of two hydrogen-carrying materials to make a single thermally neutral reaction. They found that hydrolysis of an exothermic carrier such as triethylamine-, dimethylamine-, or ammonia borane can be coupled with the complete dehydrogenation of an endothermic carrier such as indoline using a 3-to-1 molar ratio. They demonstrated that the two reactions do not inhibit each other.

Thorn et al. [18] demonstrated combining the endothermic reforming of magnesium methoxide to produce hydrogen with the exothermic reaction of the magnesium hydroxide product to magnesium carbonate.

Liu and coworkers (2011) developed a variety of carbon-boron-nitrogen (CBN) heterocycles as hydrogen storage materials [19]. One such CBN compound is 1,2 BN cyclohexane [20], which is shown in Fig. 1. Similar to other boron-nitrogen (B-N) carriers, 1,2 BN cyclohexane dehydrogenates exothermally generating 2 moles of hydrogen, ca. $4.7 \mathrm{wt} \%$ hydrogen, from the $\mathrm{B}-\mathrm{N}$ moiety to yield a molecular trimer (Rxn 1). These compounds are unique in that they can be further reacted in an endothermic reaction to remove the hydrogens from the carbon-carbon $(C-C)$ moiety to produce an aromatic compound (Rxn 2 ). These two reactions in series yield a total hydrogen storage capacity of 9.4 wt\% ( 78 g hydrogen liter ${ }^{-1}$ ). This is an example of the first class of compounds that allow for endothermic and exothermic hydrogen release from the same molecule without the need for additional reactants.

3<smiles>B1CCCCN1</smiles>

$\mathrm{mp}: 75-77^{\circ} \mathrm{C}$ d: $1.00 \mathrm{~kg} / \mathrm{L}$

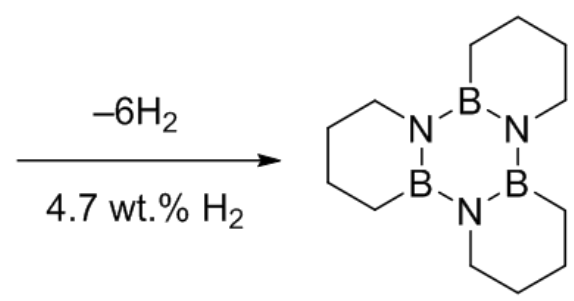

Rxn 1

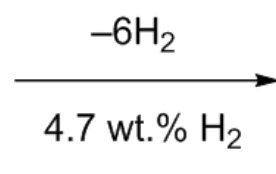

Rxn 2<smiles>C1=CB2N3C=CC=CB3N3C=CC=CB3N2C=C1</smiles><smiles>c1ccc2c(c1)CCN2</smiles>

Rxn 3

Figure 1: Exothermic hydrogen release of 1,2 BN cyclohexane from the amine borane moiety (Rxn 1) followed by the endothermic hydrogen release of the carbon backbone ( $R \times n 2)$ is the example of series reaction coupling. Exothermic hydrogen release 1,2 BN cyclohexane (Rxn 1) with the separate endothermic reaction of indoline ( $\operatorname{Rxn} 3)$ is an example of parallel reaction coupling.

The two reactions of the 1,2 BN cyclohexane compound will be used as an example for hydrogen storage materials for this analysis. It will be evaluated as a single reactant with series exothermic and endothermic reaction components. The 1,2 $\mathrm{BN}$ cyclohexane compound also will be used in combination with the separate endothermic hydrogen carrier indoline ( $\operatorname{Rxn} 3)$ as an example of parallel exothermic and 
endothermic hydrogen reactions. The research of Wechsler et al. was the basis for selecting indoline as the endothermic compound [17].

\section{Approach}

To achieve an effective exothermic/endothermic reaction coupling, four constraints on the material properties must be satisfied:

(1) The exothermic reaction must have a low enough reaction enthalpy to result in reasonable energy requirements for regeneration.

(2) The endothermic reaction must have a low enough reaction enthalpy to have acceptable hydrogen equilibrium conversion at the system minimum delivery pressure.

(3) Sufficient parity must exist between the exothermic and endothermic reaction enthalpies. With two separate carriers, the ratio of reactants can be varied to match the reaction enthalpies. For a single carrier material, this requirement is more challenging.

(4) Sufficient parity must exist between exothermic and endothermic reaction rates to allow reactions both to go to completion at similar temperatures.

(1) Exothermic Reaction Regeneration Energy Requirements. Approaches to simplify and reduce energy requirements for regeneration of hydrogen storage materials continue to be developed [21-25]. The exothermic reaction during dehydrogenation will become endothermic during the hydrogen addition and the regeneration process. As a result, in addition to the energy constraints on the endothermic reaction for dehydrogenation, energy constraints exist for the exothermic reaction during hydrogenation. With the coupled reactions, the heat from the endothermic reaction could be used during regeneration to support the regeneration of the exothermic reaction. Energy requirements for regeneration are pathway dependent and beyond the scope of this work; however, it is clear that minimizing the exothermic reaction enthalpy is required to minimize the energy required for regeneration and hydrogenation.

(2) Endothermic Reaction Hydrogen Equilibrium Pressure Requirements. While exothermic reaction conversion is not limited by hydrogen even at very high pressures, endothermic reaction conversion can be limited by hydrogen partial pressure in the range needed to supply a fuel cell ( 1 to 5 bar). The thermodynamic constraints $\left(\mathrm{K}_{\mathrm{eq}}\right)$ can be estimated from the material thermodynamic parameters of enthalpy, entropy, and Gibbs free energy $(\Delta G)$ using the van't Hoff equation:

$$
\Delta G=\Delta H-T \Delta S=-R T \ln \left(K_{e q}\right)
$$

The reaction enthalpy $(\Delta \mathrm{H})$ can be measured or calculated for a molecular complex and entropy $(\Delta S)$ is generally assumed to be equivalent to the loss of entropy for a hydrogen gas molecule, ca. $130 \mathrm{~mol}^{-1} \mathrm{~K}^{-1}$. Graetz et al. took a similar approach [12]. For the simple equilibrium reaction $A \leftrightarrow B+H_{2}$, $K_{\text {eq }}$ can be estimated as

$$
K_{e q}=\frac{X P_{H 2}}{(1-X)}
$$


where $\mathrm{X}$ is the reaction conversion and $\mathrm{P}_{\mathrm{H} 2}$ is the hydrogen equilibrium pressure. The reaction temperature to achieve $95 \%$ conversion as a function of reaction enthalpies are shown in Fig. 2 . Reaction temperatures should be limited to less than 250 to $300^{\circ} \mathrm{C}$ to address possible material decomposition and reactor design limitations. The results suggest that reaction enthalpy values must be less than $50 \mathrm{~kJ} \mathrm{~mol}^{-}$ ${ }^{1}$ to achieve $95 \%$ conversion at acceptable temperatures and pressures. This enthalpy limitation value is consistent with similar estimates found elsewhere in the literature [12].

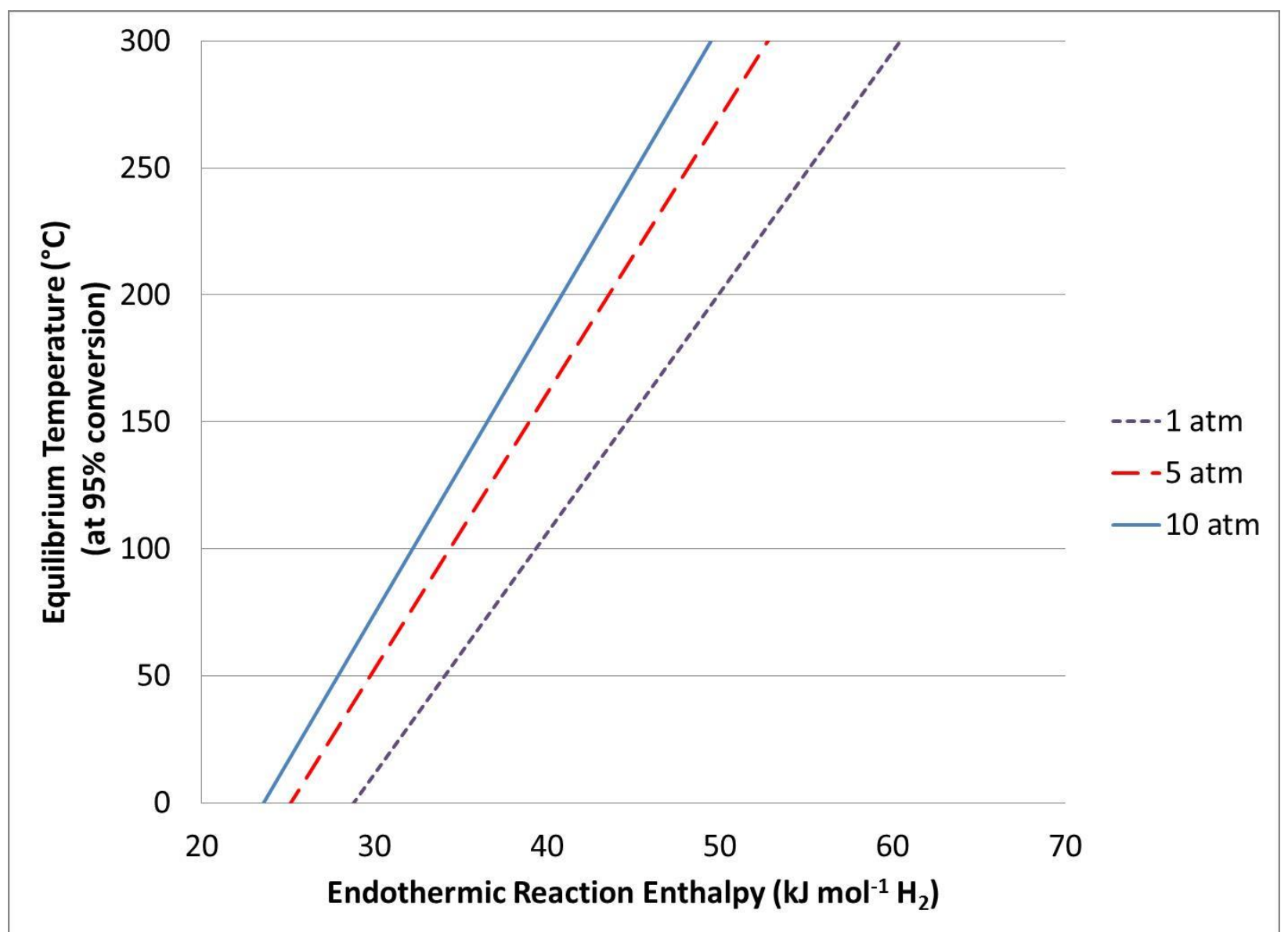

Fig. 2: Estimated equilibrium temperature to achieve $95 \%$ conversion as a function of reaction enthalpy and equilibrium hydrogen pressure.

(3) Parity between Reaction Enthalpies. Another constraint for successful coupling is that reaction enthalpies must be of similar magnitude to produce sufficient heat from the exothermic reaction to drive the endothermic reaction to completion. In the case of two separate reactants, the fraction of endothermic and exothermic hydrogen storage material introduced into the reactor can be adjusted to result in an overall auto-thermal reaction. In the case of a single constituent producing two reactions in series in which the first reaction is exothermic and the second is endothermic, the stoichiometry cannot be adjusted. Instead, to cover the disparity between the two reactions enthalpies, a fraction of the hydrogen generated can be burned to generate any additional heat required. The hydrogen loss to provide heat will reduce the system onboard efficiency. 
(4) Parity between Reaction Rates. The final constraint required that must be satisfied to couple exothermic and endothermic CBN reactions is to ensure there is sufficient parity between exothermic and endothermic reaction rates to allow both to react to completion at similar temperatures. If the temperature resulting from the exothermic reaction for complete conversion is not high enough to initiate the endothermic reaction, coupling of the reactions cannot occur.

While previous authors have suggested that coupling exothermic and endothermic reactions to improve the system efficiency of hydrogen storage materials, to our knowledge no one has previously attempted to quantify requirements for an effective reaction coupling. The purpose of this work is to use computational modeling to evaluate how the above-mentioned conditions will result in an effective coupling both for a single carrier material with an exothermic and endothermic reaction in series and for two separate exothermic and endothermic materials reacting together. To accurately assess the coupling of these reactions experimentally would require a sufficient scale to overcome heat losses, which would result in significant materials cost. In contrast, by performing the experiments using modeling, material thermodynamic and kinetic properties can be varied to determine the best conditions for coupling to provide guidance for rational design of new hydrogen storage materials.

This study will investigate two different approaches to the coupled exothermic/endothermic reaction: (1) a series reaction with neat 1,2 BN cyclohexane and (2) a parallel reaction with 1,2 BN cyclohexane as the exothermic material combined with the endothermic indoline reaction. To evaluate these two approaches, a two-dimensional axi-symmetric model in COMSOL was developed to predict the performance of these materials within a reactor. The reactor is a simple plug-flow configuration with a length-to-diameter ratio of 20 . It is filled with a $10 \%$ palladium/carbon $(\mathrm{Pd} / \mathrm{C})$ catalyst. Two assumptions are made for this system: (1) the reactants and products remain in the liquid state, and (2) hydrogen gas is removed as it is produced, resulting in no increase the velocity down the length of the reactor. Heat generated from the reaction can be conducted through the liquid both axially and radially. Heat also can be transported along a metal reactor wall and through insulation to the outside surface via conduction and natural convection. The heat and species transport equations are shown as Equations 3 and 4.

$$
\begin{aligned}
& \rho C_{p} u \cdot \nabla T=\nabla \cdot(k \nabla T)+Q \\
& \nabla \cdot\left(D_{i} \nabla C_{i}\right)+u \cdot \nabla C_{i}=R_{i}
\end{aligned}
$$

In these equations, $u$ is the velocity of the hydrogen storage material, and the reactor is assumed to be plug flow. The variables $\rho, C_{p}, k$, and $D$ are the density, heat capacity, thermal conductivity, and diffusivity, respectively. The parameters for the reactor are shown in Table 1.

Table 1: Parameters Used in the Two-Dimensional Exothermic/Endothermic Coupling Axisymmetric Model.

\begin{tabular}{|l|c|c|l|c|c|}
\hline \multicolumn{1}{|c|}{ Parameter } & Value & Units & \multicolumn{1}{|c|}{ Parameter } & Value & Units \\
\hline Reactor Length & 1.49 & $\mathrm{~m}$ & Reactor Porosity & 0.5 & \\
\hline Reactor Diameter & 0.0746 & $\mathrm{~m}$ & System Pressure & 5 & bar \\
\hline Reactor Wall Thickness & 0.01 & $\mathrm{~m}$ & Wall Density & 7800 & $\mathrm{Kg} \mathrm{m}^{-3}$ \\
\hline
\end{tabular}




\begin{tabular}{|l|c|c|l|c|c|}
\hline Insulation Thickness & 0.025 & $\mathrm{~m}$ & Wall Heat Capacity & 440 & $\mathrm{~J} \mathrm{Kg}^{-1} \mathrm{~K}^{-1}$ \\
\hline Fluid Density & 830 & $\mathrm{~kg} \mathrm{~m}^{-3}$ & $\begin{array}{l}\text { Wall Thermal } \\
\text { Conductivity }\end{array}$ & 16 & $\mathrm{~W} \mathrm{~m}^{-1} \mathrm{~K}^{-1}$ \\
\hline Fluid Heat Capacity & 3468 & $\mathrm{~J} \mathrm{~kg}^{-1} \mathrm{~K}^{-1}$ & Insulation Density & 30 & $\mathrm{Kg} \mathrm{m}^{-3}$ \\
\hline $\begin{array}{l}\text { Fluid Thermal } \\
\text { Conductivity }\end{array}$ & 0.15 & $\mathrm{~W} \mathrm{~m}^{-1} \mathrm{~K}^{-1}$ & $\begin{array}{l}\text { Insulation Heat } \\
\text { Capacity }\end{array}$ & 800 & $\mathrm{~J} \mathrm{Kg}^{-1} \mathrm{~K}^{-1}$ \\
\hline $\begin{array}{l}\text { Reactor Feed } \\
\text { Temperature }\end{array}$ & 160 & ${ }^{\circ} \mathrm{C}$ & $\begin{array}{l}\text { Insulation Thermal } \\
\text { Conductivity }\end{array}$ & 0.04 & $\mathrm{~W} \mathrm{~m}^{-1} \mathrm{~K}^{-1}$ \\
\hline $\begin{array}{l}\text { Hydrogen to Power } \\
\text { Conversion }\end{array}$ & 0.02 & $\mathrm{~g} \mathrm{~s}^{-1} \mathrm{kWe}^{-1}$ & $\begin{array}{l}\text { Exterior Convection } \\
\text { Coefficient }\end{array}$ & 10 & $\mathrm{~W} \mathrm{~m}^{-2} \mathrm{~K}^{-1}$ \\
\hline $\begin{array}{l}\text { Hydrogen Power } \\
\text { Production }\end{array}$ & 43 & $\mathrm{kWe}$ & $\begin{array}{l}\text { Ambient } \\
\text { Temperature }\end{array}$ & 20 & ${ }^{\circ} \mathrm{C}$ \\
\hline
\end{tabular}

The term $Q$ is the heat generated from the reaction and can be written as $Q=R_{1} \Delta H_{\text {exo }}+R_{2} \Delta H_{\text {endo. }}$. The reaction rates can be written based on the following equations in which the reaction rates for the exothermic and endothermic reactions are shown in Equations 5 and 6 , respectively, with $C_{i}$ representing the concentrations of the products and reactants.

$$
\begin{aligned}
& R_{1}=k_{1} C_{A}^{n} \\
& R_{2}=k_{2}\left(C_{B}^{n}-C_{C}^{n} p_{H 2} / K_{e q}\right)
\end{aligned}
$$

The Arrhenius reaction rate for each reaction is expressed as follows:

$$
k_{i}=A_{i} e^{\frac{-E_{a}}{R T}}
$$

With specific reactor dimensions, the scale of the reactor becomes important. In this case, we assumed the hydrogen storage system was designed for a light-duty vehicle. Work in the Hydrogen Storage Engineering Center of Excellence has determined that the hydrogen from a $43 \mathrm{kWe}$ storage system with a ballast tank will meet the hydrogen demand for the US06, UDDS, Cold FTP, and Hot SCO3 drive cycles even if they have peak demands of $80 \mathrm{kWe}$ [26]. As a result, this work will be based on a $43 \mathrm{kWe}$ hydrogen production requirement for automotive applications.

\section{Thermodynamic and Kinetic Data Used in the Model}

To obtain the kinetics of the exothermic reaction for hydrogen release from the CBN compound, a gas burette system was used to measure the isothermal production rate of hydrogen using $10 \% \mathrm{Pd} / \mathrm{C}$ catalyst at temperatures ranging from 80 to $140^{\circ} \mathrm{C}$ [27]. The amount of hydrogen produced was measured and normalized to the number of hydrogen equivalents generated. Data generated in these five experiments were fit simultaneously. Using a solver routine to minimize the coefficient of determination while adjusting the kinetic parameters, we estimated the reaction order, activation energy and pre-exponential factor. The best fit of the exothermic reaction was described as a first-order reaction in series with a 
second-order reaction. Experimental data and the empirical fit resulting from this analysis are shown in Fig. 3.

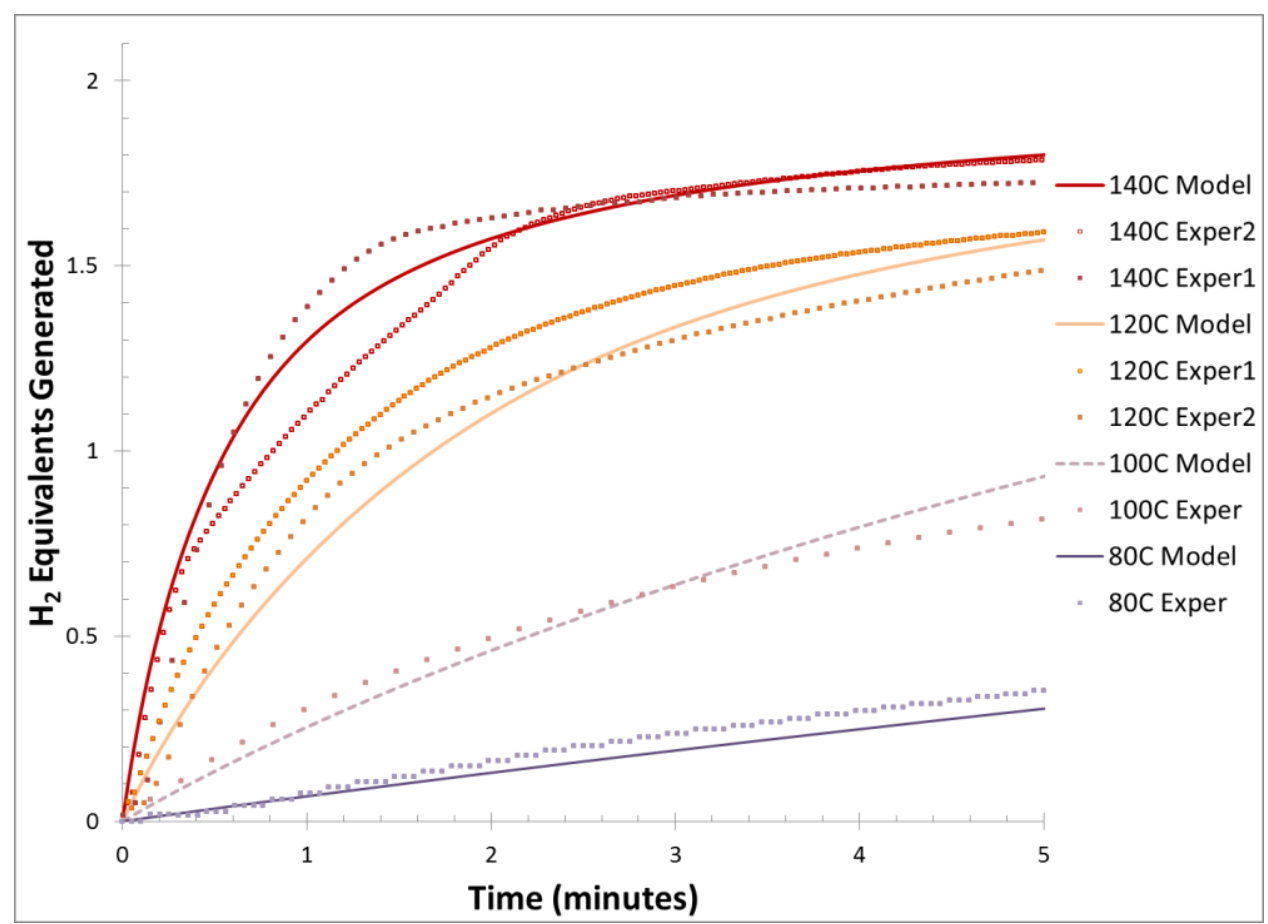

Fig. 3: Experimental results and model fit for the exothermic dehydrogenation of $1,2 \mathrm{BN}$ cyclohexane in the presence of $10 \% \mathrm{Pd} / \mathrm{C}$ ( $7.5 \mathrm{mg}$ of $\mathrm{Pd} / \mathrm{C}$ and $15 \mathrm{mg} \mathrm{CBN}$ )

Reaction calorimetry was used to measure the enthalpy for the exothermic release of hydrogen from the $1,2 \mathrm{BN}$ cyclohexane. Assuming that the two exothermic processes observed by calorimetry in Fig 4 each correspond to one equivalent of hydrogen, the first equivalent was assumed to be $-40 \mathrm{~kJ} \mathrm{~mol}^{-1}$ hydrogen and the second equivalent assume to be $-20 \mathrm{~kJ} \mathrm{~mol}^{-1}$ hydrogen ( 2 moles of hydrogen mole ${ }^{-1}$ of $\mathrm{CBN}$ ). This is comparable to the heat release of two equivalents of hydrogen from ammonia borane to form polyimine borane [28-30]. 


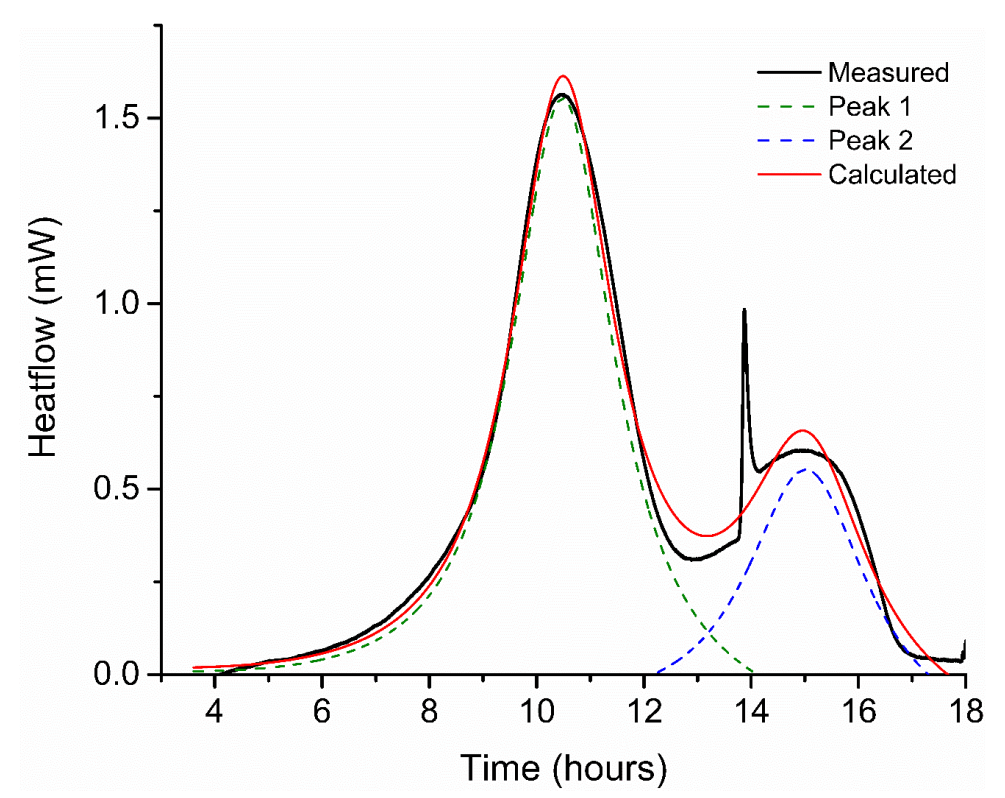

Fig. 4: Fit of the exothermic peaks in the ramped calorimetry experiment with $1,2 \mathrm{BN}$ cyclohexane

The enthalpy, $\Delta \mathrm{H}$ ca. $+62 \mathrm{~kJ} \mathrm{~mol}^{-1}$ hydrogen (two moles of hydrogen) can be estimated for the endothermic release of hydrogen from 1,2 BN cyclohexane based on published data from the calorimetry experiment for the reverse reaction, hydrogenation of 1,2-azaborine [31]. This estimated enthalpy value is lower than the enthalpy for hydrogenation of the all-carbon backbone (i.e., $\Delta \mathrm{H} \mathrm{ca} .69 \mathrm{~kJ} \mathrm{~mol}^{-1}$ hydrogen for cyclohexane) and compares very well with the experimental and calculated $\Delta \mathrm{H}$ for hydrogen release from piperidine (i.e., $62.3 \mathrm{~kJ} \mathrm{~mol}^{-1}$ hydrogen). As such, it appears that the addition of a boron atom to the cyclic ring has no added benefit relative to the addition of nitrogen [32].

The kinetic results of the dehydrogenation reaction of indoline were taken from Dean et al. [33] who also performed the reaction using $10 \% \mathrm{Pd} / \mathrm{C}$. First-order rate constants were measured as $1.8 \times 10^{-4} \mathrm{~s}^{-1}$ and $5.9 \times 10^{-4} \mathrm{~s}^{-1}$ with $1 \mathrm{~mol} \%$ loading of catalyst at 100 and $120^{\circ} \mathrm{C}$, respectively. The rate constant was shown to be proportional to the mass of palladium used. These values were then used to predict the preexponential factor and activation energy for this reaction with $66 \mathrm{~mol} \%$ catalyst loading in the reactor bed, consistent with the kinetic experiments performed for the CBN compound.

The thermodynamic and kinetic parameters used for modeling based on the experiments described above and analyses are shown in Table 2. Because no experimental data has been published for the endothermic reaction kinetics for hydrogen release from the carbon backbone of $C B N$, we used a parametric approach to predict a range of possible kinetics that would be acceptable to achieve high conversion levels.

Table 2: Kinetic and Thermodynamic Parameters Used for Coupling Reactions.

\begin{tabular}{|c|c|c|c|c|c|}
\hline & \multicolumn{2}{|c|}{$\begin{array}{c}\text { Exothermic } \\
\text { Parameter }\end{array}$} & $\begin{array}{c}\text { Endothermic } \\
\text { 1,2 BN } \\
\text { 1,2 BN cyclohexane }\end{array}$ & $\begin{array}{c}\text { Endothermic } \\
\text { Indoline }\end{array}$ & Units \\
\hline Reaction Enthalpy & -40 & -20 & 62 & 52 & $\begin{array}{c}\mathrm{kJ} \mathrm{mol}^{-1} \\
\text { hydrogen }\end{array}$ \\
\hline
\end{tabular}




\begin{tabular}{|l|c|c|c|c|c|}
\hline Pre-Exponential Factor & $3.35 \times 10^{8}$ & 7.15 & unknown & $1.61 \times 10^{8}$ & $\mathrm{~s}^{-1}$ \\
\hline Activation Energy & 77.4 & 52.9 & unknown & 72.3 & $\mathrm{~kJ} \mathrm{~mol}^{-1}$ \\
\hline Reaction Order & 1 & 2 & 1 & 1 & \\
\hline
\end{tabular}

\section{Modeling Results}

Series and parallel exothermic/endothermic coupling reactions were modeled based on the kinetic and thermodynamic properties shown in Table 2. As discussed previously, the series reaction evaluates the $\mathrm{CBN}$ compound with the dehydrogenation reaction of both the B-N moiety (exothermic) and the $\mathrm{C}-\mathrm{C}$ moiety (endothermic) in series. The parallel reaction evaluates $\mathrm{CBN}$ compound dehydrogenation of the B-N moiety (exothermic) and the catalytic reaction of indoline (endothermic). As no kinetic values are available for the endothermic dehydrogenation reaction of the $\mathrm{C}-\mathrm{C}$ moiety for $1,2 \mathrm{BN}$ cyclohexane, this reaction rate is assumed to be bounded at its maximum by the rate of the exothermic reaction.

The model predicts the conversion of the endothermic reactions to be limited to 30 to $40 \%$ for both the series and parallel reactions. These poor conversion levels are the result of thermodynamic equilibrium constraints at 5-bar hydrogen. In the case of the series reactions of 1,2 BN cyclohexane, only $30 \%$ conversion is predicted in spite of the exothermic temperature increase to $311^{\circ} \mathrm{C}$. In the case of the parallel reaction with indoline, endothermic conversions of only $34 \%$ were achieved when the concentrations of indoline and 1,2 BN cyclohexane were adjusted so that the reaction was thermally neutral. Higher 1,2 BN cyclohexane-to-indoline ratios result in significantly higher maximum temperatures but only slightly higher conversions.

These results indicate that to achieve the desired reaction conversions of near $90 \%$, materials must be identified with endothermic reaction enthalpies of closer to $40 \mathrm{~kJ} \mathrm{~mol}^{-1}$ [16]. At these lower reaction enthalpies, reaction kinetics control conversion rather than being limited by thermodynamics. As a result, all subsequent modeling was performed assuming similar reaction kinetics for 1,2 BN cyclohexane and indoline, but the endothermic reaction enthalpy is assumed to be $40 \mathrm{~kJ} \mathrm{~mol}^{-1}$ hydrogen. Typical results from this analysis are shown in Fig. 5. The direction of flow is shown from top to bottom through the center of the tube. Steady-state distributions of the temperature and exothermic and endothermic conversions are shown. 


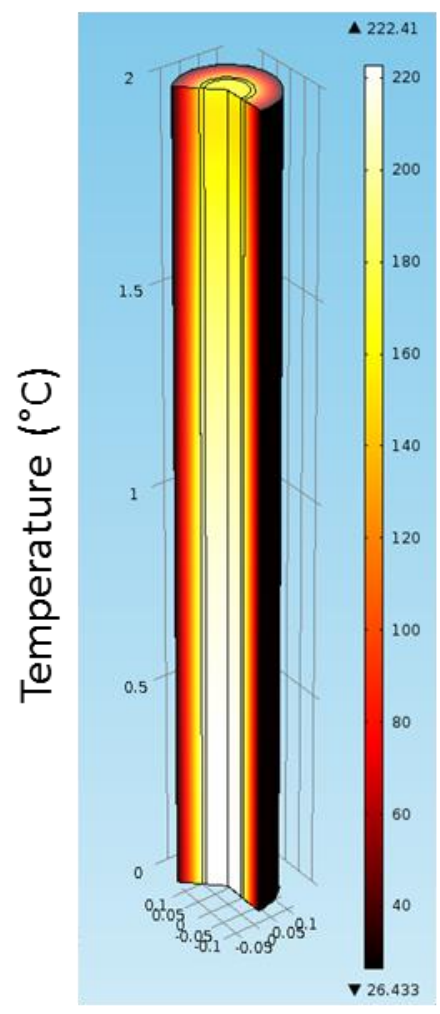

(a)

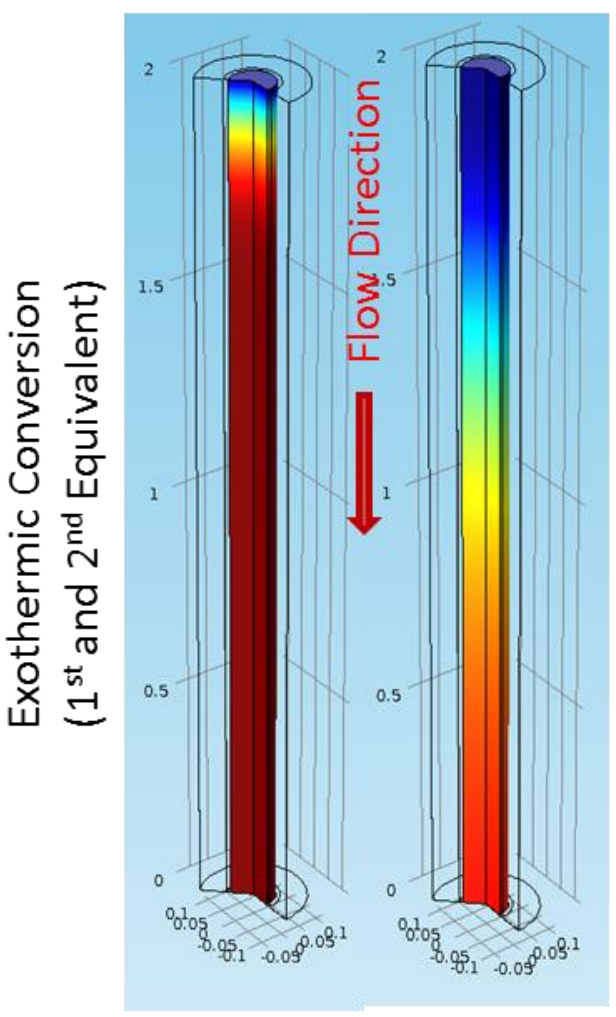

(b)

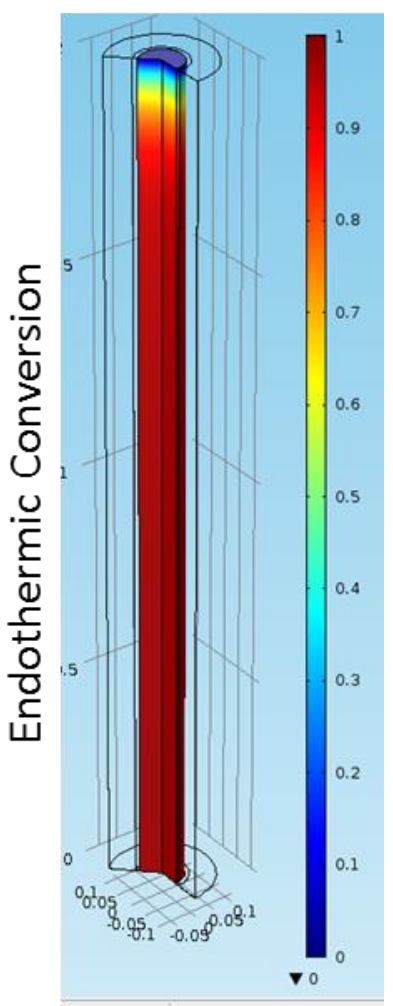

(c)

Fig. 5: Typical reactor modeling prediction from COMSOL for (a) Temperature, (b) Exothermic Conversion, and (c) Endothermic Conversion distribution within the reactor. Results shown are parallel reactions with equimolar 1,2 BN cyclohexane and indoline with a feed temperature of $160^{\circ} \mathrm{C}$.

A sensitivity analysis was performed on the model with the parallel reaction of $C B N$ and indoline assuming full conversion will yield $43 \mathrm{kWe}$. The results of this analysis are shown in Table 3. With a 1,2 BN cyclohexane-to-indoline (CBN:I) molar ratio of 0.67 , the reactions should be thermally neutral. However, under these conditions, production of the CBN second hydrogen equivalent does not go to completion. By increasing the $\mathrm{CBN}$ :I ratio, the maximum reaction temperature increases and conversion of the second equivalent of the exothermic reaction improves. In addition, the model predicts $62 \%$ conversion for the endothermic reaction operating independently as compared to $>90 \%$ when coupled. The model prediction for the exothermic reaction operated independently results in nearly complete conversion of the second equivalent. This condition also results in the highest hydrogen production. However, it also produces a maximum reaction temperature that is more than $160^{\circ} \mathrm{C}$ higher than that produced by the coupled reaction. A small amount of indoline significantly reduces the reaction temperature while only slightly reducing hydrogen production.

Table 3: Results of the Sensitivity Analysis with CBN Compound and Indoline Reactions in Parallel

\begin{tabular}{|c|c|c|c|c|c|c|c|c|}
\hline \multicolumn{2}{|c|}{ Reaction Enthalpy } & \multirow{2}{*}{$\begin{array}{l}\text { CBN:I } \\
\text { Molar } \\
\text { Ratio }\end{array}$} & \multicolumn{2}{|c|}{$\begin{array}{l}\text { Exothermic } \\
\text { Conversion }\end{array}$} & \multirow{2}{*}{$\begin{array}{c}\text { Endothermic } \\
\text { Conversion }\end{array}$} & \multirow{2}{*}{$\begin{array}{l}\text { Maximum } \\
\text { Reaction } \\
\text { Temp. } \\
\left({ }^{\circ} \mathrm{C}\right)\end{array}$} & \multirow{2}{*}{$\begin{array}{c}\text { Theoretical } \\
\text { Excess Heat }^{2} \\
(\mathrm{~kW})\end{array}$} & \multirow{2}{*}{$\begin{array}{c}\text { Hydrogen } \\
\text { Produced } \\
\left(\text { mole s }^{-1}\right)\end{array}$} \\
\hline $\begin{array}{c}\text { Exo. } \\
\left(\mathrm{kJ} \mathrm{mol}^{-1}\right)\end{array}$ & $\begin{array}{c}\text { Endo. }{ }^{1} \\
\left(\mathrm{~kJ} \mathrm{~mol}^{-1}\right)\end{array}$ & & $\begin{array}{l}1^{\text {st }} \\
\text { Eq. }\end{array}$ & $\begin{array}{l}2^{\text {nd }} \\
\text { Eq. }\end{array}$ & & & & \\
\hline
\end{tabular}




\begin{tabular}{|c|c|c|c|c|c|c|c|c|}
\hline$-40 /-20$ & 40 & 0.5 & 1 & 0.12 & 0.91 & 160 & 2.2 & 0.4 \\
\hline$-40 /-20$ & 40 & 0.67 & 1 & 0.25 & 0.93 & 160 & 0 & 0.37 \\
\hline$-40 /-20$ & 40 & 1 & 1 & 0.58 & 0.97 & 178 & -2.9 & 0.33 \\
\hline$-40 /-20$ & 40 & 1.3 & 1 & 0.80 & 0.98 & 204 & -4.7 & 0.32 \\
\hline \multicolumn{7}{|l|}{} \\
\hline$-40 /-20$ & N/A & 0 & 1 & 0.99 & N/A & 366 & -12.9 & 0.43 \\
\hline N/A & 40 & $\infty$ & N/A & N/A & 0.62 & 160 & 17.2 & 0.27 \\
\hline
\end{tabular}

${ }^{1}$ Results assume a reduction in endothermic enthalpy from 51 to $40 \mathrm{~kJ} \mathrm{~mol}^{-1}$ for indoline.

${ }^{2}$ Positive values indicate additional heat is required. Negative heat values indicate additional heat is produced.

A sensitivity analysis was performed for the series reaction of 1,2 BN cyclohexane with both the exothermic dehydrogenation of the $\mathrm{B}-\mathrm{N}$ moiety and the endothermic dehydrogenation of the $\mathrm{C}-\mathrm{C}$ moiety. The kinetics of the exothermic reaction was based on experimental data and the kinetics of the endothermic reaction was allowed to vary. The endothermic reaction enthalpy was adjusted down to 40 $\mathrm{kJ} \mathrm{mol}^{-1}$, and the exothermic/endothermic enthalpy ratio was varied between 0 and 1.125 . The resulting data is shown in Fig. 6 . The model predictions indicate that reaction enthalpy more strongly impacts the endothermic reaction conversion and maximum reaction temperature than does kinetics. Reaction kinetic ratios can vary more than two orders of magnitude difference before conversion decreases significantly. However, even a $25 \%$ difference in reaction enthalpy results in a similar reduction in the endothermic reaction conversion. The sensitivity of the maximum reaction temperature also is provided. Maximum reaction temperature is more strongly coupled to kinetics than endothermic reaction conversion and increases with higher kinetic ratios. This impact is especially pronounced at reaction enthalpy ratios near unity. Higher maximum reaction temperatures result from a larger disparity between the exothermic and endothermic reaction rates. 

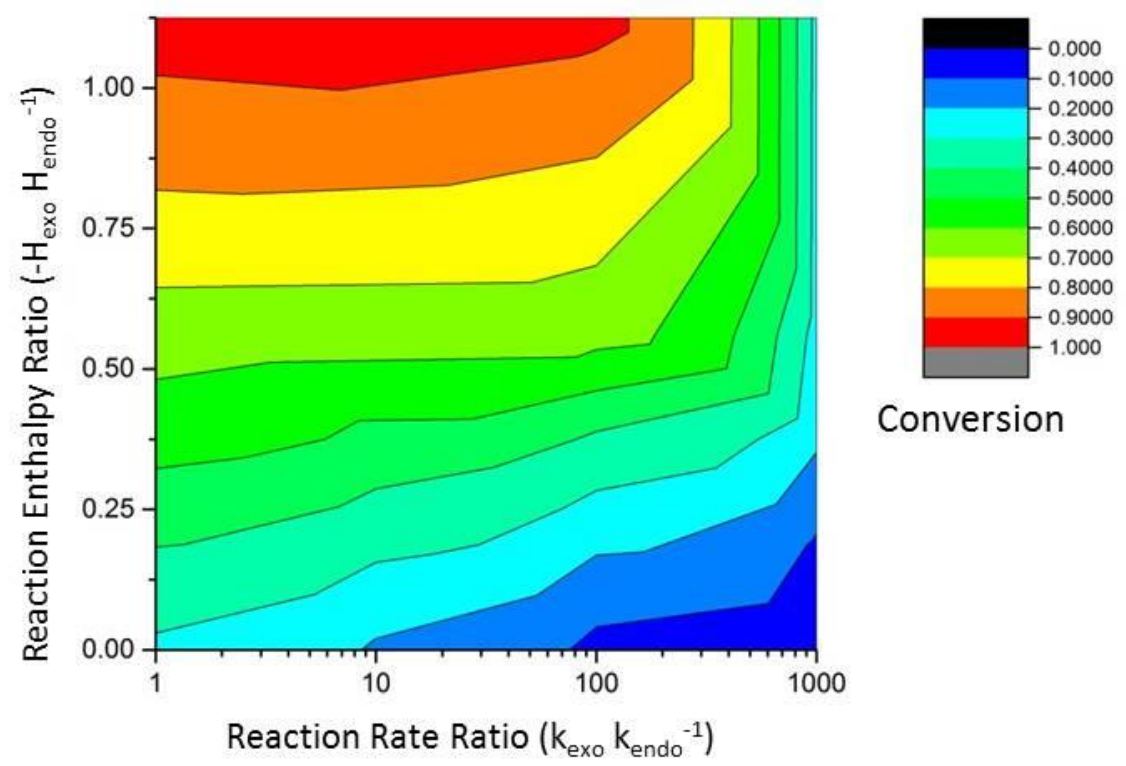

\section{Conversion}

(a)
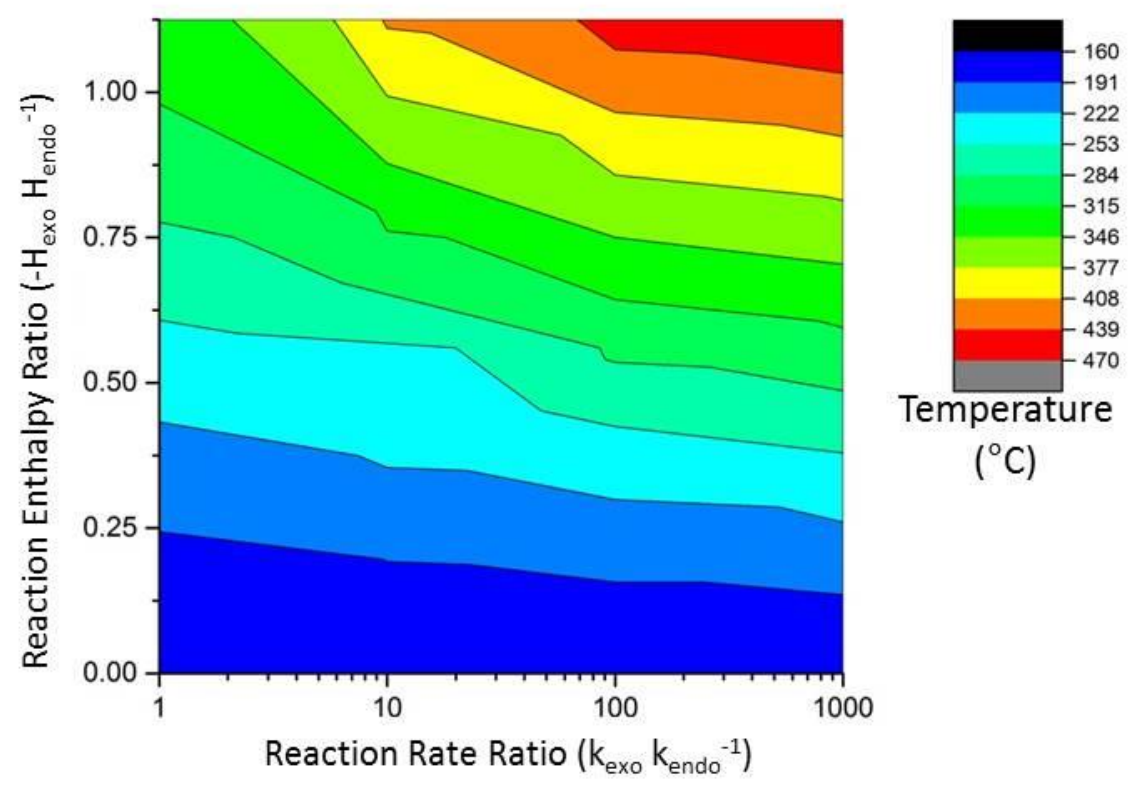

$\left({ }^{\circ} \mathrm{C}\right)$

(b)

Fig. 6: Sensitivity analysis comparing $C B N$ kinetics ratio $\left(k_{\text {exo }} \mathrm{k}_{\text {endo }}{ }^{-1}\right)$ and reaction enthalpy ratio $\left(\mathrm{H}_{\text {exo }}\right.$ $\mathrm{H}_{\text {endo }}{ }^{-1}$ ) for exothermic and endothermic reactions in series. Results are shown for (a) endothermic reaction conversion and (b) reaction temperature.

In addition to the simple plug-flow reactor, two other reactor designs are also considered: (1) one similar to a Continuously Stirred Tank Reactor (CSTR) and (2) a U-shaped or two-pass reactor. The first reactor design has a length-to-diameter ratio of two. We assumed the reactor was well mixed, and as a result, we set the thermal conductivity of the reactor to three orders of magnitude higher than the simple plug- 
flow reactor $\left(150 \mathrm{~W} \mathrm{~m}^{-1} \mathrm{~K}^{-1}\right)$. We evaluated this reactor because it is the bounding case in which mixing prevents a large exotherm at the inlet of the reactor and a large endotherm at the exit. For the U-shaped or two-pass reactor, the reactants flow down through a center tube and then back up in an annulus around the central tube. This reactor design allows heat transfer from the high temperature zone at the inlet of the reactor to conduct to the low temperature endothermic zone near the exit of the reactor. To create the flow, a packed bed with Darcy's flow is assumed, and the pressure distribution is adjusted to have the same residence time as the simple plug-flow reactor.

A typical result from the two-pass plug-flow reactor is shown in Fig. 7. As can be seen, some of the heat produced from the exothermic reaction occurring at the inlet of the reactor is transferred to the reactor exit. Comparisons of the endothermic reaction conversion predicted for series reactions with the singlepass reactor, two-pass reactor, and CSTR are shown in Fig. 8. Endothermic conversion for the CSTR is much lower than the other two reactors. The double-pass reactor shows nearly identical endothermic conversion to the single-pass plug-flow reactor. A separate analysis was performed with the thermal conductivity of the fluid increased by three orders of magnitude, similar to the CSTR. Endothermic conversion decreases sharply with reaction rate ratio, and resultant conversion values are very similar to those obtained for the CSTR.

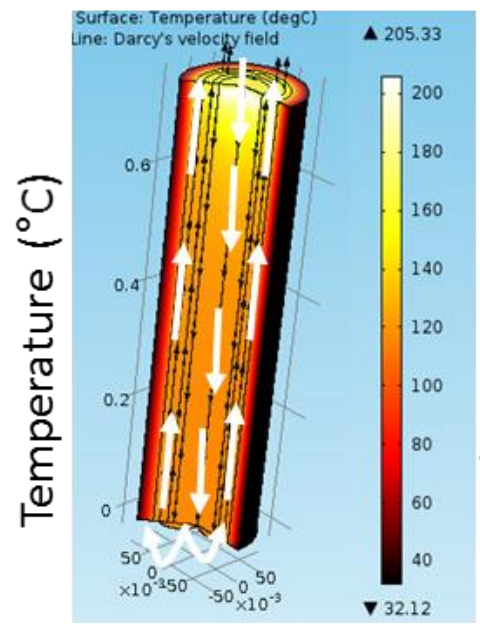

(a)

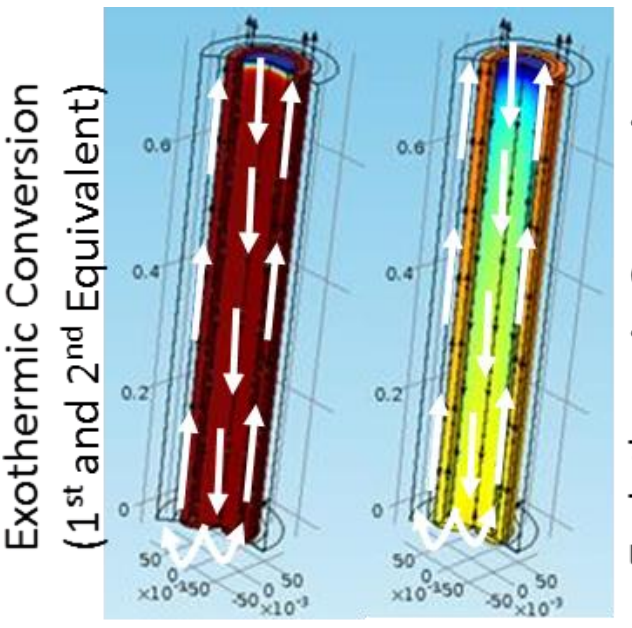

(b)

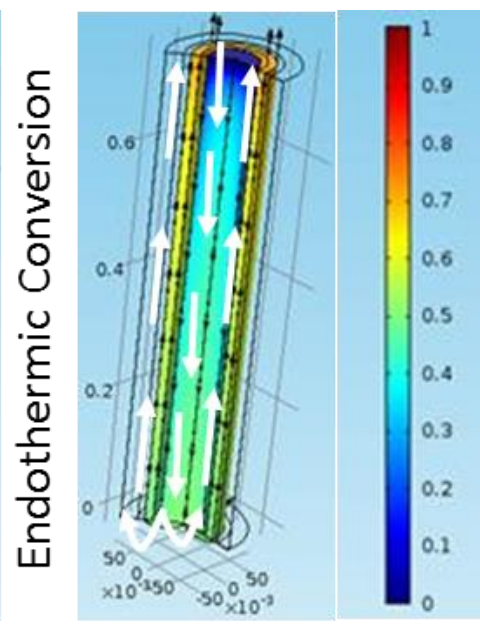

(c)

Fig. 7: Typical COMSOL model result for a double-pass plug-flow reactor: (a) reaction temperature, (b) exothermic reaction conversion, and (c) endothermic reaction conversion. 


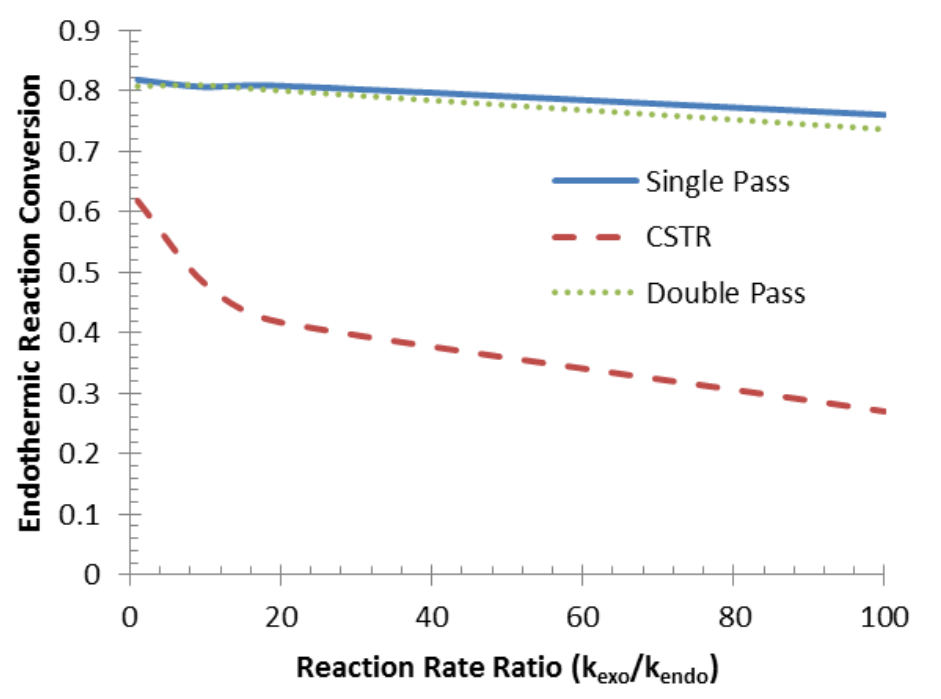

Fig. 8: Endothermic reaction conversion as a function of the reaction rate ratio for series coupled reactions with a CSTR reactor and single- and double-pass reactors.

These results indicate that the configuration of the reactor does impact the endothermic reaction conversion. Trying to minimize the temperature increase, by either the double-pass reactor or the CSTR, does not improve the reaction conversion. In fact, a decrease in conversion results. Because of the exponential relationship between reaction rate and temperature, it appears that a high-temperature zone created by the exothermic reaction allows the endothermic reaction to proceed more quickly than a slightly warmer low temperature zone created by the alternative designs. The primary limitation in using the plug-flow reactor is that the high-temperature zone could decompose or volatilize the products, produce side reactions, or damage the reactor. Based on this study, the impact of the parameters appear to be reaction enthalpy ratio > reaction rate ratio > reactor design.

\section{Conclusions and Recommendations}

The purpose of this work is to understand key factors in coupling exothermic and endothermic reactions for use as hydrogen storage materials. The reaction thermodynamics are key to achieving good coupling. Endothermic enthalpy values of greater than $40 \mathrm{~kJ} \mathrm{~mol}^{-1}$ result in unacceptably low reaction conversions. Reactions in series and in parallel are studied. In both cases, conditions exist for which significant improvement in endothermic reaction conversion and/or reduction in maximum reaction temperature were achieved when the two reactions are coupled.

Based on the sensitivity analysis, an exothermic temperature increase is required to obtain reasonable reaction conversion as compared to a true auto-thermal reaction. Differences in reaction enthalpies for the exothermic and endothermic reactions are more important than differences in their reaction kinetics. A simple single-pass reactor design appears to provide a better endothermic reaction conversion than other designs considered. Alternative designs meant to transfer heat more uniformly across the entire reaction zone resulted in reduced conversion levels.

Additional research is needed to identify compounds with kinetics and thermodynamics that will better couple the reaction. Also, the materials must be stable at room temperature, remain in the liquid phase 
before and after the reaction, and have sufficiently high hydrogen capacities. If such compounds can be found, the coupled reaction may improve their performance.

\section{Disclaimer}

This report was prepared as an account of work sponsored by an agency of the U.S. Government. Neither the U.S. government nor any agency thereof, nor any of their employees, makes any warranty, express or implied, or assumes any legal liability or responsibility for the accuracy, completeness, or usefulness of any information, apparatus, product, or process disclosed or represents that its use would not infringe privately own rights. Reference herein to any specific commercial product, process or service by trade name, trademark, manufacturer or otherwise does not necessarily constitute or imply its endorsement, recommendation, or favoring by the U.S. Government or any agency thereof. The views and opinions of authors expressed herein do not necessarily state or reflect those of the U.S. Government or any agency thereof.

\section{Acknowledgements}

This work was done at PNNL and sponsored by the U.S. Department of Energy. Special thanks to Dr. ShihYuan Liu (Boston College) for providing the CBN materials and directing this project. The authors would also like to thank Ned Stetson and Grace Ordaz for their outstanding support. Battelle operates PNNL for the Department of Energy under contract DE-AC05-76RLO1830.

\section{References}

[1] Q. L. Zhu and X. Qiang, "Liquid organic and inorganic chemical hydrides for high-capacity hydrogen storage," Energy Environ. Sci., vol. 8, pp. 478-512, 2015.

[2] Q. Zhang, Y. Wu, X. Sun and J. Ortega, "Kinetics of catalytic hydrolysis of stabilized sodium borohydride solutions," Ind. Eng. Chem. Res., vol. 46, pp. 1120-1124, 2007.

[3] A. V. Safronov, S. S. Jalisatgi, H. B. Lee and M. F. Hawthorne, "Chemical hydrogen storage using polynuclear borane anion salts," Int. J. Hydrogen Energy, pp. 234-239, 2011.

[4] L. Li, S. Li, Y. Tan, Z. Tang, W. Cai, Y. Guo, Q. Li and X. Yu, "Hydrogen generation from hydrolysis and methanolysis of guanidinium borohydride," J. Phys. Chem., vol. 116, p. 14218, 2012.

[5] Q. Xu and M. Chandra, "A portable hydrogen generation system: Catalytic hydrolysis of ammoniaborane," J. Alloys Compd., Vols. 446-447, pp. 729-732, 2007.

[6] Z. Huang, X. Chen, T. Yisgedu, E. A. Meyers, S. G. Shore and J. Zhao, "NH4(B3H8): New synthesis, structure, and hydrolytic hydrogen release," Inorg. Chem., vol. 50, p. 3738, 2011. 
[7] D. Schubert, D. Neiner, M. Bowden, S. Whittemore, J. Holladay, Z. Huang and T. Autrey, "Capacity enhancement of aqueous borohydride fuels for hydrogen storage in liquids," J. Alloys Compd., 2015.

[8] Z. Huang and T. Autrey, "Boron-nitrogen-hydrogen ("BNH") compounds: recent developments in hydrogen storage, applications in hydrogenation and catalysis, and new synthesis," Energy Environ. Sci., pp. 9257-9268, 2012.

[9] A. Karkamkar, S. M. Kathmann and G. K. Schenter, "Thermodynamic and structural investigations of ammonia borohydride, a solid with a highest content of thermodynamically and kinetically accessible hydrogen," Chem. Mater., vol. 21, pp. 4356-4358, 2009.

[10] D. Neiner, A. Karkamkar and M. Bowden, "Kinetic and thermodynamic investigation of hydrogen release of ethane 1,2-di-amineborane," Energy Environ. Sci., vol. 4, pp. 4187-4193, 2011.

[11] M. Bowden and T. Autrey, "Characterization and mechanistic studies of the dehydrogenation of NHxBHx materials," Curr. Opin.Solid Sstate Mater. Sci., vol. 15, pp. 73-79, 2011.

[12] J. Graetz, D. Wolstenhom, G. Pez, L. Klebanoff, S. McGrady and A. Cooper, "Development of offboard reversiable hydrogen storage materials," in Hydrogen Storage Technology Materials and Applications, Boca Raton, FL, CRC Press, 2013, pp. 239-328.

[13] K. Noelker and J. Johanning, "Autothermal Reforming: A flexible syngas route with future potential," in Nitrogen \& Syngas 2010 International Conference, Bahrain, February 28 - March 3, 2010.

[14] T. P. Tiemersma, T. Kolkman, J. Kuipers and M. van Sint Annaland, "A Novel Autothermal Reactor Concept for Thermal Coupling of the Exothermic Oxidative Coupling and Endothermic Steam Reforming of Methane," Chem. Eng. J., vol. 203, pp. 223-230, 2012.

[15] R. C. Ramaswamy, P. Ramachardran and M. Dudukovic, "Coupling exothermic and endothermic reaction in adiabatic reactors," Chemical Engineering Science, vol. 63, pp. 1654-1667, 2008.

[16] A. C. Cooper, "Design and devleopment of new carbon-based sorbent systems for an effective containment of hydrogen," Air Products and Chemicals, Inc., Allentown, PA, 2012.

[17] D. Wechsler, Y. Cui, D. Dean, B. Davis and P. Jessop, "Production of $\mathrm{H}_{2}$ from Combined Endothermic and Exothermic Hydrogen Carriers," J. Am. Chem. Soc., vol. 130, pp. 17195-17203, 2008.

[18] D. Thorn, W. Tumas, K. Ott and A. Burrell, "Composition and methods for storing and releasing hydrogen". U.S.A. Patent 2007/0183967 A1, 9 August 2007. 
[19] W. Luo, P. Campbell, L. Zakharov and S. Liu, "A single-component liquid phase hydrogen storage material," J. Am. Chem. Soc., vol. 133, pp. 19326-19329, 2011.

[20] S. Y. Liu, "Novel Carbon(C)-Boron(B)-Nitrogen(N)-Containing $\mathrm{H}_{2}$ Storage Materials," in 2014 Annual Merit Review, Washington, D.C., June 17, 2014.

[21] C. Reller and F. O. R. L. Mertens, "A Self-Contained Regeneration Scheme for Spent Ammonia Borane Based on the Catalytic Hydrodechlorination of $\mathrm{BCl} 3$," Angew. Chem. Int. Ed., vol. 51, pp. 11731-11735, 2012.

[22] M. T. Mock, R. G. Potter, D. M. Camaioni, J. i, W. G. Dougherty, W. S. Kassel, B. Twamley and D. L. DuBois, "Thermodynamic Studies and Hydride Transfer Reactions from a Rhodium Complex to BX3 Compounds," J. Am. Chem. Soc., vol. 131, pp. 14454-14465, 2009.

[23] P. V. Ramachandran and P. D. Gagare, "Preparation of ammonia borane in high yield and purity, methanolysis, and regeneration," Inorg. Chem., vol. 46, pp. 7810-7817, 2007.

[24] S. Hausdorf, F. Baitalow, G. Wolf and F. O. R. L. Mertens, "Chemical kinetics of Ru-catalyzed ammonia borane hydrolysis," Int. J. Hydrogen Energy, pp. 608-614, 2008.

[25] B. L. Davis, D. A. Dixon, E. B. Garner, J. C. Gordon, M. H. Matus, B. Scott and F. H. Stephens, "Efficient Regeneration of Partially Spent Ammonia Borane Fuel," Agnew. Chem. Int. Ed., vol. 48, pp. 6812-6816, 2009.

[26] K. Brooks, R. P. Pires and K. Simmons, "Development and validation of a slurry model for chemical hydrogen storage in fuel cell vehicle applications," J. Power Sources, vol. 271, pp. 504-515, 2014.

[27] F. Zheng, S. D. Rassat, D. J. Heldebrandt and D. D. Caldwell, "Automated gas burette system for evolved hydrogen measurements," Rev. Sci. Instrum., vol. 79, no. 084103, 2008.

[28] Z. Huang and T. Autrey, "Boron-nitrogen-hydrogen ("BNH") compounds: recent developments in hydrogen storage, applications in hydrogenation and catalysis, and new syntheses," Energy Environ. Sci., vol. 5, pp. 9257-9268, 2012.

[29] T. Autrey, M. Bowden and A. Karkamkar, "Control of hydrogen release and uptake in amine borane molecular complexes: Thermodynamics of ammonia borane, ammonium borohydride, and the diammoniate of diborane," Faraday Disc., vol. 151, p. 157, 2011.

[30] F. Baitalow, J. Baumann, G. Wolf, K. Jaenicke-Rößler and G. Leitner, "Thermal decomposition of B$\mathrm{N}-\mathrm{H}$ compounds investigated by using combined thermoanalytical methods," Thermochim. Acta, vol. 391, pp. 159-168, 2002. 
[31] P. G. Campbell, E. R. Abbey, D. Neiner, D. J. Grant, D. A. Dixon and S.-Y. Liu, "Resonance Stabilization Energy of 1,2-Azaborines: A Quantitative Experimental Study by Reaction Calorimetry," J. Am. Chem. Soc. , vol. 132, pp. 18048-18050, 2010.

[32] E. Clot, O. Eisenstein and R. H. Crabtree, "Computational structure-activity relationships in $\mathrm{H}_{2}$ storage: how placement of $\mathrm{N}$ atoms affects release temperatures in organic liquid storage materials," Chem. Commun., p. 2231-2233, 2007.

[33] D. Dean, B. Davis and P. Jessop, "The effect of temperature, catalyst and sterics on the rate of Nheterocycle dehydrogenation for hydrogen storage," New J. Chem., vol. 35, pp. 2147-422, 2011.

\section{Nomenclature}
$\mathrm{A}_{\mathrm{i}}$ : Arrhenius factor $\left(\mathrm{s}^{-1}\right)$
C: concentration $\left(\mathrm{mol} \mathrm{m}^{-3}\right)$
$C_{p}$ : heat capacity $\left(\mathrm{J} \mathrm{kg}^{-1} \mathrm{~K}^{-1}\right)$
$\mathrm{D}_{\mathrm{i}}$ : diffusivity $\left(\mathrm{m} \mathrm{s}^{-2}\right)$
$E_{\mathrm{a}}$ : activation energy $\left(\mathrm{kJ} \mathrm{mol}^{-1}\right)$
$\mathrm{k}$ : thermal conductivity $\left(\mathrm{W} \mathrm{m}^{-1} \mathrm{~K}^{-1}\right)$
$K_{\text {eq: }}$ : equilibrium constant
$\mathrm{k}_{\mathrm{i}}$ : reaction rate $\left(\mathrm{s}^{-1}\right)$
$\mathrm{P}_{\mathrm{H} 2}$ : hydrogen partial pressure (bar)
$\mathrm{Q}$ : heat $\left(\mathrm{kW} \mathrm{m}^{-3}\right)$
$\mathrm{R}$ : universal gas constant $\left(\mathrm{J} \mathrm{mol}^{-1} \mathrm{~K}^{-1}\right)$
$\mathrm{R}_{\mathrm{i}}$ : reaction rate $\left(\mathrm{mol} \mathrm{m}^{-3} \mathrm{~s}^{-1}\right)$
$\mathrm{T}$ : temperature $(\mathrm{K})$
$\mathrm{u}$ : velocity $\left(\mathrm{m} \mathrm{s}^{-1}\right)$
$\mathrm{X}$ : conversion fraction
$\Delta \mathrm{G}$ : Gibbs free energy $\left(\mathrm{kJ} \mathrm{mol}^{-1}\right)$
$\Delta \mathrm{H}$ : reaction enthalpy $\left(\mathrm{kJ} \mathrm{mol}^{-1}\right)$
$\Delta \mathrm{S}$ : reaction entropy $\left(\mathrm{kJ} \mathrm{mol}^{-1}\right)$
$\rho:$ density $\left(\mathrm{kg} \mathrm{m}^{-3}\right)$ 